\title{
Effects of different methods to control the parasitic weed Phelipanche ramosa (L.) Pomel in processing tomato crops
}

\author{
Grazia Disciglio, ${ }^{1}$ Francesco Lops, ${ }^{1}$ Antonia Carlucci, ${ }^{1}$ Giuseppe Gatta, ${ }^{1}$ Annalisa Tarantino, ${ }^{1}$ \\ Laura Frabboni, ${ }^{1}$ Filomena Carriero, ${ }^{2}$ Emanuele Tarantino' \\ ${ }^{1}$ Department of Agricultural Food and Environmental Science, University of Foggia; \\ ${ }^{2}$ Research Centre Metapontum Agrobios, Metaponto (MT), Italy
}

\begin{abstract}
The root-parasitic weed Phelipanche ramosa (L.) Pomel represents a major problem for processing tomato crops. The control of this holoparasitic plant is difficult, and better understanding of treatment methods is needed to develop new and specific control strategies. This study investigated 12 agronomic, chemical, biological and biotechnological strategies for the control of this parasitic weed, in comparison with the untreated situation. The trial was carried out in 2014 at the Department of Agriculture, Food and the Environment of the University of Foggia (southern Italy), using processing tomato plants grown in pots filled with soil from a field that was heavily infested with $P$. ramosa. After transplantation, top dressing was performed with 70 $\mathrm{kg} \mathrm{ha}^{-1}$ nitrogen. A randomised block design with 3 replicates (pots) was adopted. During the growing cycle of the tomato, at 70,75, 81 and 88 days after transplantation, the number of parasitic shoots (branched plants) that had emerged in each pot was determined, and the leaf chlorophyll of the plants was measured using a soil-plantanalysis-development meter. At harvesting on 8 August 2014, the major quanti-qualitative yield parameters were determined, including marketable yield, mean weight, dry matter, soluble solids, and fruit colour. The results show lower chlorophyll levels in the parasitised tomato plants, compared to healthy plants. None of the treatments provided
\end{abstract}

\footnotetext{
Correspondence: Emanuele Tarantino, Department of Agricultural Food and Environmental Science, University of Foggia, via Napoli 25, 71121 Foggia, Italy.

Tel.: +39.0881.589237.

E-mail: emanuele.tarantino@unifg.it
}

Key words: Control methods; broomrape; Phelipanche ramosa; processing tomato; quality.

Acknowledgements: this study was carried out within the project OROPOMVEG approved by the Apulia region within the Linee Guida, 20122014 for research and experimentation in agriculture.

Received for publication: 21 April 2015.

Revision received: 12 October 2015.

Accepted for publication: 26 October 2015.

(C) Copyright G. Disciglio et al., 2016

Licensee PAGEPress, Italy

Italian Journal of Agronomy 2016; 11:681

doi:10.4081/ija.2016.681

This article is distributed under the terms of the Creative Commons Attribution Noncommercial License (by-nc 4.0) which permits any noncommercial use, distribution, and reproduction in any medium, provided the original author(s) and source are credited. complete control against $P$. ramosa. However, among the methods tested, Radicon ${ }^{\circledR}$ biostimulant (Radicon, Inc., Elk Grove Village, IL, USA), compost activated with Fusarium oxysporum, nitrogen and sulphur mineral fertilisers, Enzone ${ }^{\mathrm{TM}}$ soil fumigant (Elliott Chemicals Ltd., Auckland, New Zealand), and a resistant tomato genotype mitigated the virulence of the attacks of this parasite. These effects should be improved by combining some of these treatments, especially for gradual and continued reduction in the seed bank of the parasite in the soil. For the tomato yields across the different treatments, there were no significant differences seen; however, the yields showed an improving trend for treatments with lower presence of the $P$. ramosa weed.

\section{Introduction}

The broomrape Phelipanche ramosa (L.) Pomel is synonymous with Orobanche ramosa L. (Joel et al., 2007), and it is a chlorophyll-lacking root holoparasitic plant of many dicotyledonous species. It can cause severe damage to several cultivated species, especially in semi-arid regions of the world (Linke and Saxena, 1989). These are weedy plants that have stems that are usually branched above the ground (except with very small plants), and they are usually $15 \mathrm{~cm}$ to $25 \mathrm{~cm}$ high, with many uniform flowers that are pale blue/purple on the outside.

In the Apulia region (southern Italy), this weed is particularly devastating for fields of processing tomato crops, where it endangers the future existence of this crop (Zonno et al., 2000). Heavy infestation arises because $P$. ramosa can produce large numbers of seeds (up to 500,000 per plant) (Zindahl, 1993) of very small dimensions (ca. 0.2$0.3 \mathrm{~mm}$ ), and also because in the absence of a host plant, these seeds can remain viable in the soil for extended periods (up to 20 years) (Linke and Saxena, 1989). This thus makes it difficult for any crop rotation to be efficient.

P. ramosa attacks tomato roots early in the growing season, at 14 days to 28 days after transplanting (DAT), depending on the temperature conditions, and the shoot usually emerges from 35 DAT to 56 DAT (Eizenberg et al., 1998). The parasitised tomato plants initially show stunted growth, with the subsequent decreased production as a consequence of a reduction in their ability to use nutrients and to absorb water. Measures to successfully contain the problems due to this parasitic weed need to be targeted at: i) reduction of the existing $P$. ramosa seed bank in the soil; ii) prevention of further seed production; and iii) prevention of seed dissemination. These objectives are mutually dependent. The seed bank in the soil can only be reduced when the new seed input is smaller than the output, through successful germination, pathogens, seed predation, or natural death of the seeds (Lonsdale, 1993; Westerman et al., 2003; van Mourik et al., 2005; van Mourik and Stomph, 2011).

Several methods for the control of this parasite have been investigated, including the use of physical, chemical, agronomic, biological 
and biotechnological methods (Habimana et al., 2013). However, the main concern is that to date there are no practical methods that are effective, economical and protective against this parasite, and that the effects of any control agent also depend on the environmental conditions. For this reason, an integrated approach is needed for the control of $P$. ramosa, in which different methods are combined to maintain the parasite populations below threshold levels for crop damage (Joel, 2000; Amsellem et al., 2001; Goldwasser and Kleifeld, 2004; Rubiales and Fernandez-Aparicio, 2012; Goldwasser and Rodemburg, 2013). Moreover, there is the need to overcome the hazardous and toxic use of chemical methods to control this parasite, as these can be damaging to both humans and animals, and can lead to environmental pollution.

Thus, many studies are now focussing more attention on the development of alternative methods to control $P$. ramosa, such as the use of agronomic, biotechnological, biological and non-chemical control methods. Among these, greenhouse experiments were carried out over different growing seasons in southern Italy (Sicily region) to determine the effects of soil solarisation on tomato pests and weeds (Lombardo et al., 2012). This study showed that soil solarisation provides a good level of control of $P$. ramosa.

$P$. ramosa tends to be associated with less fertile soil conditions, and high levels of nitrogen fertiliser and additional compounds have been shown to have a suppressive effect. Therefore, agronomic methods of its control include the use of organic and inorganic compounds. Indeed, organic compounds, such as compost, recycled wastewater (e.g., from olive mills, agro-industrial) and biostimulants applied to the soil, are widely used to increase the organic matter in cropping systems, the effects of which can include a reduction in the germination and growth of many weeds, included $P$. ramosa (Haider and Sidahmad, 2000). The addition of such organic compounds to the soil is suitable because they are rich sources of microorganisms that can suppress plant diseases, and they thus represent an interesting potential biological control method (Cubero and Moreno, 1979; Tardioli et al., 1997; Litterick et al., 2004; Saad et al., 2007; Alfano et al., 2011; Disciglio et al., 2015).

Inorganic compounds have been studied for the reduction of $P$. ramosa infestation. Some of these studies have shown that increases in the levels of nitrogen and phosphorous in the soil through the application of fertilisers can reduce germination of this parasitic weed, and consequently reduce its infestation rates (Bebawi, 1981; Pieterse, 1991; Jamil et al., 2011). Sulphur compounds have also been used to lower soil pH, for the control of various weeds (Buchanan et al., 1975; Abu-Irmaileh, 1981; Zollinger and Kells, 1991). Moreover, the combination of chicken manure and elemental sulphur was shown to be an effective management practice to control $P$. ramosa in potato and eggplant (Haidar and Sidahmed, 2006).

In recent years, biological control agents such as fungi have received more attention for the reduction of $P$. ramosa seed germination (Amsellem et al., 2001; Dor et al., 2007; Joel et al., 2007; Sauerborn et al., 2007). Among the several fungal species used, Fusarium oxysporum Schltdl isolated from diseased $P$. ramosa has been shown to be highly virulent against this parasite. This activity of some fungal strains has been attributed to their production of various phytotoxic metabolites that can inhibit $P$. ramosa seed germination (Zonno and Vurro, 2002; Azam et al., 2003; Boari and Vurro, 2004; Abouzeid and El-Tarabil, 2010). Also, many rhizosphere microorganisms, such as arbuscular mycorrhizal fungi, have been implicated in the biological control of parasitic weeds through a reduction in their seed germination (Lendzemo et al., 2007; Lopez-Ráez et al., 2011). An alternative and/or complementary approach for the control of Phelipanche spp. in plants is through genetic improvements or selection, and the use of new plant genotypes that are resistant to these parasites (Dor et al., 2010; Gressel, 2013).

Therefore, the present study was conducted to investigation further methods to control the $P$. ramosa root parasite in processing tomato crops. These methods included agronomic techniques, such as organic composts (i.e., olive-mill wastewater, biostimulants), for which there appears not to be any information on their control of $P$. ramosa in the literature, and the application of inorganic sulphur and nitrogen fertilisers to the soil. Also, biological techniques (e.g., F. oxysporium, arbuscular mycorrhizal fungi) and biotechnological techniques (e.g., resistant plants) were used. The objectives of the present study were to: i) determine the effects of each of the experimental treatments for the control of $P$. ramosa during tomato crop stages; and ii) evaluate their effects on the qualitative and quantitative aspects of the processing tomato crop.

\section{Materials and methods}

\section{Experimental site and treatments}

This study was carried out in 2014 at the Department of Agriculture, Food and the Environment, University of Foggia (southern Italy) (41 ${ }^{\circ}$ 27' 27'N; 15 $31^{\prime}$ 56' E; $75 \mathrm{~m}$ a.s.l.). Processing tomato plants were grown in parallelepiped pots (length $\times$ width $\times$ height, $63 \times 32 \times 28 \mathrm{~cm}$ ) that were filled with soil taken from a field that was known to be heavily infested by $P$. ramosa. The pots were placed in an open field. The experimental site was in a typical semi-arid zone that was characterised by a Mediterranean climate, with mild winters and warm dry summers. According to long-term climate data, the annual mean rainfall and temperature are $526 \mathrm{~mm}$ and $10.9^{\circ} \mathrm{C}$, respectively (Caliandro et al., 2005).

Different tomato cultivars were used, as also indicated in Table 1: Docet, Red setter, Red setter tilling and Taylor mycorrhized with Glomus intraradices. The tomato seedlings were transplanted into pots on 8 May, 2014, at two plants per pot, in sandy-clay soil (United State Department of Agriculture classification) with the following characteristics: sand, 45.6\%; loam, 20.0\%; clay, 24.4\%; organic matter (Walkley and Black's method), 1.30\%; assimilable phosphorus, $86 \mathrm{ppm}\left(\mathrm{P}_{2} \mathrm{O}_{5}\right.$; Olsen's method); exchangeable potassium, $1430 \mathrm{ppm}\left(\mathrm{K}_{2} \mathrm{O}\right.$; Schollemberger's method); total nitrogen, $0.89 \%$ (Kieldahl's method); $\mathrm{pH}$ (in water), 8.14; electrical conductivity, $0.49 \mathrm{dSm}^{-1}$; field capacity $(-0.03 \mathrm{MPa}), 34.9 \%$ dry weight (dw); wilting point (-1.5 MPa), $20 \% \mathrm{dw}$; and bulk density, $1.38 \mathrm{Mg} \mathrm{m}^{-3}$. Pre-transplantation fertiliser was applied to the soil with a distribution equivalent to $100 \mathrm{~kg} \mathrm{ha}^{-1}$ nitrogen, $60 \mathrm{~kg} \mathrm{ha}^{-1} \mathrm{P}_{2} \mathrm{O}_{5}$ and $20 \mathrm{~kg} \mathrm{ha}^{-1}$ sulphur. During the crop cycle, 70 $\mathrm{kg} \mathrm{ha}^{-1}$ nitrogen was added. The source of the nitrogen was ammonium nitrate. The irrigation schedule (i.e., times and volumes of water supplied to the pots) was according to the soil water-balance approach. Therefore, the gravimetric soil moisture was measured weekly by the weighing of each pot, to evaluate the water depletion from the soil. The water then supplied with the irrigation re-established the soil water content to field capacity. The 12 experimental treatments to control the parasitic weed were compared with untreated plants, as reported in Table 1. A randomised block design with three replicates (pots) for each of the treatments was adopted.

The biological control included $F$. oxysporum inoculum $\left(1 \times 10^{6} \mathrm{~mL}^{-1}\right)$ alone and combined with compost, and tomato plants with mycorrhizal fungi. This $F$. oxysporum used for biological control was isolated from necrotic shoots and inflorescences of $P$. ramosa, collected from infested tomato crops in the Capitanata area (Foggia province, southern Italy). The $F$. oxysporum isolates were identified on the basis of their culture and microscopic features. The reference fungal strains were maintained on potato dextrose agar plates and are stored at $4{ }^{\circ} \mathrm{C}$ for further studies, in the culture collection of the Department of Science of Agriculture, Food and the Environment, of the University of Foggia, Italy. For the mycorrhizal fungi method, the tomato roots of cv. Taylor 
tomato plants were inoculated with a culture of $G$. intraradices N.C. Schenck \& G.S. Sm. directly by the nursery seedling farm. Finally, for the resistant plant approach, a new improved tomato genotype was used that was developed in the genetic background of cv. Red setter tomato at the Research Centre Metapontum Agrobios, using a targeting-induced local lesions in genomes (tilling) platform that is used to provide new improved tomato genotypes with particular characteristics of interest (Minoia et al., 2010; Silletti, et al., 2013). This new cv. Red setter tilling was improved through the reduction in the synthesis of the plant hormone strigolactone, which leads to greater tolerance of the tomato plants to infection with $P$. ramosa. For the chemical method, only the fumigant Enzone ${ }^{\mathrm{TM}}$ soil fumigant (Elliott Chemicals Ltd., Auckland, New Zealand) was tested. Enzone ${ }^{\mathrm{TM}}$ (Elliott Chemicals Ltd.) is a solution of sodium tetrathiocarbonate that was applied 60 days prior to seedling transplantation into the soil.

Throughout the tomato crop cycle, $P$. ramosa infestation was assessed according to the number of emerged shoots (branched plants) in each pot at 70,75, 81 and 88 DAT. Moreover, considering that part of the water and mineral nutrients move from the host to the parasite, a chlorophyll meter [soil-plant-analysis-development (SPAD); Minolta Camera Co. Ltd., Osaka, Japan] was used to estimate the nutritional status of the tomato plants (Yang et al., 2014). The SPAD values were read at the centre of each leaflet of the third fully expanded leaf blade of the tomato plants, at 53 DAT and 76 DAT, for all of the treatments that were compared. In addition, the SPAD values were determined separately at $53 \mathrm{DAT}$ on 12 parasitised and 12 non-parasitised plants.

\section{Tomato plant and fruit characterisation}

The tomato fruit were harvested at full-stage maturity on 8 August 2014, when the marketable yield (MY, $\mathrm{kg} \mathrm{pot}^{-1}$ ) from each pot was measured. On a sample of 10 fruit, the following major quantity-quality yield parameters were determined: mean weight (in g), soluble solids content when fresh (in ${ }^{\circ} \mathrm{Brix}$ ), and dry matter content (as \% fruit fresh matter) (AOAC, 1990). The colour index (Jiménez-Cuesta et al., 1981) and the L coordinate (Francis and Clydesdale, 1975; Favati et al., 2009) were measured using a spectrophometer (CM-700d; Minolta Camera Co. Ltd.), on four randomly selected areas of the fruit surface.

\section{Statistical analysis}

The whole dataset was tested according to the basic assumptions for the analysis of variance (ANOVA). The normal distribution of the experimental error and the common variance of the experimental error were verified through Shapiro-Wilk and Bartlett's tests, respectively. The differences between the means were determined using Tukey's test at the $5 \%$ probability level. The ANOVA for quanti-qualitative parameters was only carried out on cv. Docet.

Due to the correlations observed among the different quanti-qualitative parameters of the tomato fruit, these were jointly considered in a multivariate approach, and were processed statistically for principal component analysis (PCA). Before performing the PCA, the values of each parameter were standardised. A factorial analysis was also performed on the PCA values, using the varimax method. All of the graphical representations were carried out using the SigmaPlot software (Systat Software, Chicago, IL, USA).

\section{Results}

\section{Climate conditions of the experimental site}

The 10-day (decade) mean climate parameters recorded during the 2014 growing season are reported in Figure 1. The mean temperature increased almost linearly through the summer, from $15.1^{\circ} \mathrm{C}$ on 1 May, to $24.2^{\circ} \mathrm{C}$ on 1 August. Through the season, the total evaporation varied from $35 \mathrm{~mm}$ to $60 \mathrm{~mm}$, while the total rainfall was only high in the second decade of June, with $50 \mathrm{~mm}$ recorded.

\section{Effects of treatments on the control of Phelipanche ramosa}

The early emerged shoots appeared at 53 DAT on cv. Docet treated with sulphur. As shown in Figure 2, P. ramosa shoots were detected for almost all of the tested treatments. There were no significant differences among the treatments for 70 DAT and 75 DAT, whereas significant differences were seen at $81 \mathrm{DAT}$ and $88 \mathrm{DAT}$. At the end of the crop cycle (88 DAT), the mean numbers of $P$. ramosa shoots varied from 5.0 to 19.7 according to treatment. In comparison with the untreated control, reductions of $68.1 \%, 61.7 \%, 49.0 \%$ and $59.8 \%$ were recorded for treatments $\mathrm{T}_{5}, \mathrm{~T}_{7}, \mathrm{~T}_{10}$ and $\mathrm{T}_{11}$, respectively. For the Red setter and Red setter tilling cultivars $\left(\mathrm{T}_{6}, \mathrm{~T}_{8}\right.$, respectively) there were significantly more emerged shoots of $P$. ramosa at 88 DAT in each pot with $\mathrm{T}_{6}$ than $\mathrm{T}_{8}(8.7 \pm 0.21$ vs $16.3 \pm 2.9 ; \mathrm{P} \leq 0.05)$, while for $\mathrm{T}_{9}$ (cv. Red setter) there was a mean of $11.0 \pm 3.1$ emerged shoots at 88 DAT (data not shown).

Table 1. Treatments performed in this study.

\begin{tabular}{|c|c|c|}
\hline Cultivar & Treatment & Code \\
\hline Docet & Fusarium oxysporum isolated from diseased Phelipanche ramosa tubercles at $1 \times 10^{6} \mathrm{CFU} \mathrm{mL}^{-1}, 7$ days before seedling transplantation & $\mathrm{T}_{1}$ \\
\hline Docet & Olive-mill wastewater at $80 \mathrm{~m}^{3} \mathrm{ha}^{-1}$ (in agreement with Italian law; Italian Regulation, 1996), 60 days before seedling transplantation & $\mathrm{T}_{2}$ \\
\hline Docet & Olive-mill wastewater $\left(160 \mathrm{~m}^{3} \mathrm{ha}^{-1}\right), 60$ days before seedling transplantation & $\mathrm{T}_{3}$ \\
\hline Docet & Sumus organic fertiliser of a manure mixture of cattle, poultry and domestic stallatic $\left(3.3 \mathrm{t} \mathrm{ha}^{-1}\right), 7$ days before seedling transplantation & $\mathrm{T}_{4}$ \\
\hline Docet & Root soaked in concentrated Radicon ${ }^{\circledR}$ (Radicon, Inc.) at transplanting time and during the first three irrigations (as 1.5\% solution) & $\mathrm{T}_{5}$ \\
\hline Docet & Compost inoculated with $F$. oxysporum at $1 \times 10^{6} \mathrm{CFU} \mathrm{mL}^{-1}\left(4.0 \mathrm{t} \mathrm{ha}^{-1}\right), 7$ days before seedling transplantation & $\mathrm{T}_{7}$ \\
\hline Docet & Sulphus [8 t ha-1 of Grenver Zolfo 87; Cifo s.p.a, S. Giorgio di Piano (BO), Italy] incorporated before seedling transplantation & $\mathrm{T}_{10}$ \\
\hline Docet & Nitrogen fertiliser, with nitrogen ( $80 \mathrm{~kg} \mathrm{ha}^{-1}$ ammonium sulphate), before seedling transplantation & $\mathrm{T}_{11}$ \\
\hline Docet & Enzone $^{\mathrm{TM}}$ (Elliott Chemicals Ltd.) (261 $\mathrm{g}$ ha $^{-1}$ sodium tetrathiocarbonate) incorporated 60 days before seedling transplantation & $\mathrm{T}_{12}$ \\
\hline Docet & Control, no treatment & $\mathrm{T}_{13}$ \\
\hline Red setter & Control & $\mathrm{T}_{6}$ \\
\hline $\begin{array}{l}\text { Red setter } \\
\text { tilling }\end{array}$ & A tomato cultivar obtained with tilling (targeting induced local lesions in genomes) technology & $\mathrm{T}_{8}$ \\
\hline Taylor & Mycorrhized with Glomus intraradices & $\mathrm{T}_{9}$ \\
\hline
\end{tabular}




\section{Effects on the nutritional status of the tomato plants}

As shown in Figure 3, at the early stage of the tomato crop cycle (53 DAT), when it was possible to differentiate between uninfected and infected plants, the mean leaf chlorophyll (measured as SPAD) of the uninfected tomato plants $(49.3 \pm 4.7)$ was significantly greater than that of the infected plants $(43.2 \pm 2.3 ; \mathrm{P} \leq 0.05)$.

\section{Effects on quali-quantitative parameters}

Table 2 gives the effects of the different experimental treatments on the quanti-qualitative traits of the processing tomato cultivar Docet. For the marketable yield of this tomato cultivar, there were no differences among the treatments. When considering only the treatments using the same tomato cv. Docet, where there were smaller numbers of emerged $P$. ramosa shoots this resulted in numerically increased marketable yields (by about 15\%) compared to the other conditions, although this did not reach significance among the treatments (Figure 4). The improved Red setter tilling cultivar $\left(\mathrm{T}_{8}\right)$ also gave a higher marketable yield (mean, $1.40 \mathrm{~kg} \mathrm{plant}^{-1}$ ) compared to the derived Red setter cultivar (mean, 1.15 $\mathrm{kg}_{\mathrm{g}} \mathrm{plant}^{-1}$ ), which was related to the lower parasitic infection (data not shown). For the different parameters of the tomato fruit that were analysed for tomato cv. Docet, only the mean weight, L coordinate, and dry matter content showed significant differences (Table 2). The mean weight of the tomato fruit was significantly higher $(\mathrm{P}=0.05)$ for the Sumus organic fertiliser treatment (Sumus Italia srl, Modena, Italy) $\left(\mathrm{T}_{4}, 63.80 \mathrm{~g}\right)$ compared to the control tomato plants (42.93 g), and was only significantly different with respect to the treatment with the compost inoculated with $F$. oxysporum $\left(\mathrm{T}_{7}, 44.90 \mathrm{~g}\right)$.

The different treatments significantly $(\mathrm{P} \leq 0.05)$ affected the $\mathrm{L}$ colour parameter of the tomato fruit, with higher values for the nitrogen fertiliser $\left(\mathrm{T}_{11}, 41.24\right)$ and the Enzone ${ }^{\mathrm{TM}}$ soil fumigant (Elliott Chemicals Ltd.) $\left(\mathrm{T}_{12}, 42.33\right)$ compared to the control $\left(\mathrm{T}_{13}, 35.49\right)$ and the other experimental treatments. Across all of the treatments, the mean dry matter content ranged from $5.22 \%$ to $6.69 \%$, and this was significantly higher for the $F$. oxysporum soil treatment $\left(\mathrm{T}_{1}, 6.69 \%\right)$ than for the lowdose olive mill wastewater $\left(\mathrm{T}_{2}, 5.31 \%\right)$ and the nitrogen fertiliser $\left(\mathrm{T}_{11}\right.$, $5.22 \%$ ). According to the PCA (Table 3 and Figure 5), the six variables related to the qualitative traits of the tomato fruit were reduced to two factors that explained $74.24 \%$ of the total variance. The first factor (for $39.71 \%$ of the total variance) was mainly associated with the colour coordinate (L), the colour index, the soluble solids content, and the dry matter content (scores, 0.649, 0.691, 0.797 and 0.668, respectively), so this factor can be considered as a quality factor. The second factor (for

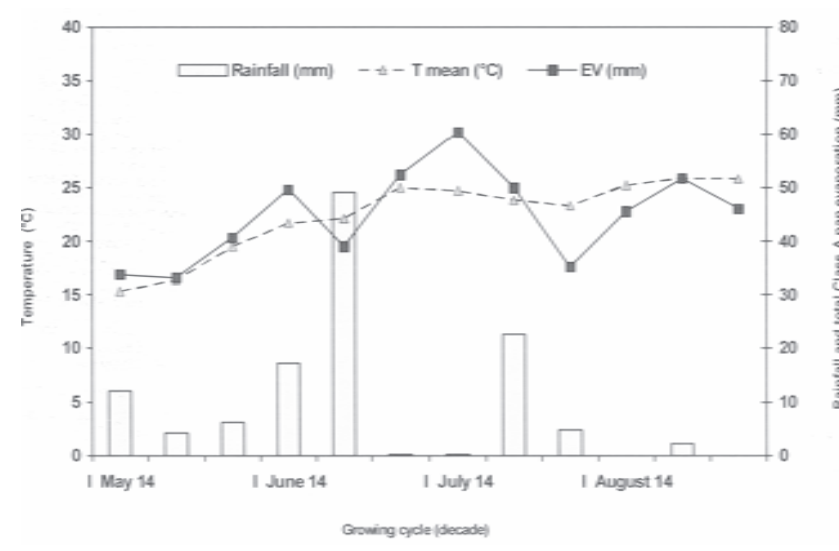

Figure 1. Mean temperature (T), total 10-day (decade) rainfall, and class A pan evaporation (EV) during the tomato-growing season.

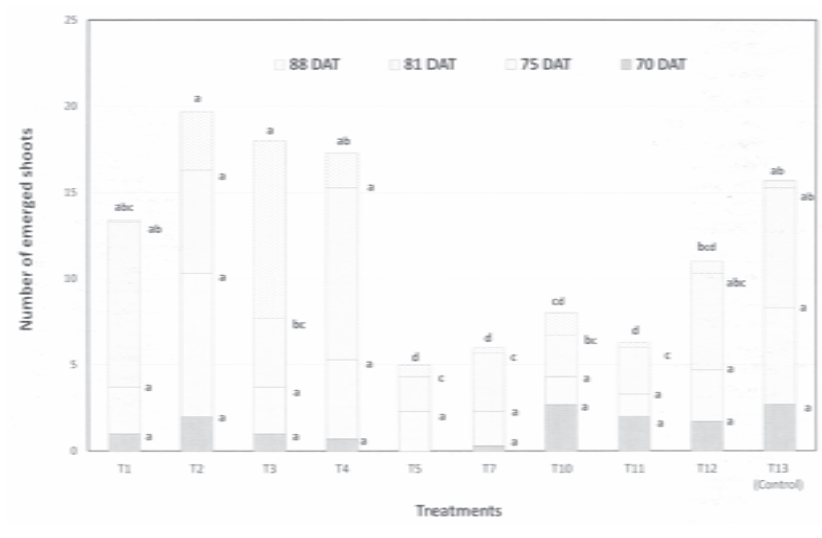

Figure 2. Number of emerged shoots of Phelipanche ramosa at $70,75,81$ and 88 days after transplantation (DAT) in each pot, for the different treatments (see Table 1). Values with different letters on cumulative values of each DAT and for each treatment are significantly different at $\mathrm{P}=\mathbf{0 . 0 5}$ (Tukey's test).

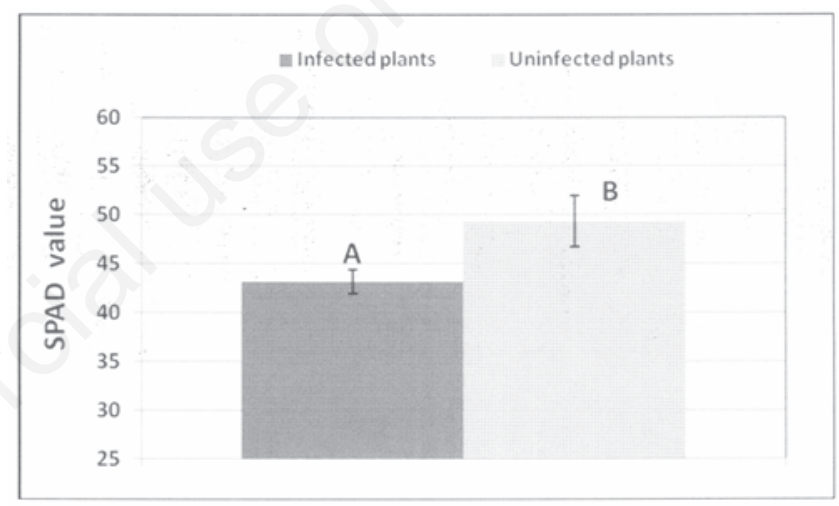

Figure 3. Mean soil-plant-analysis-development (SPAD) values for infected and uninfected tomato plants measured at 53 days after transplantation. Data are means \pm standard errors for plants calculated for $n=24$ (12 leaves $\times 2$ leaflets).

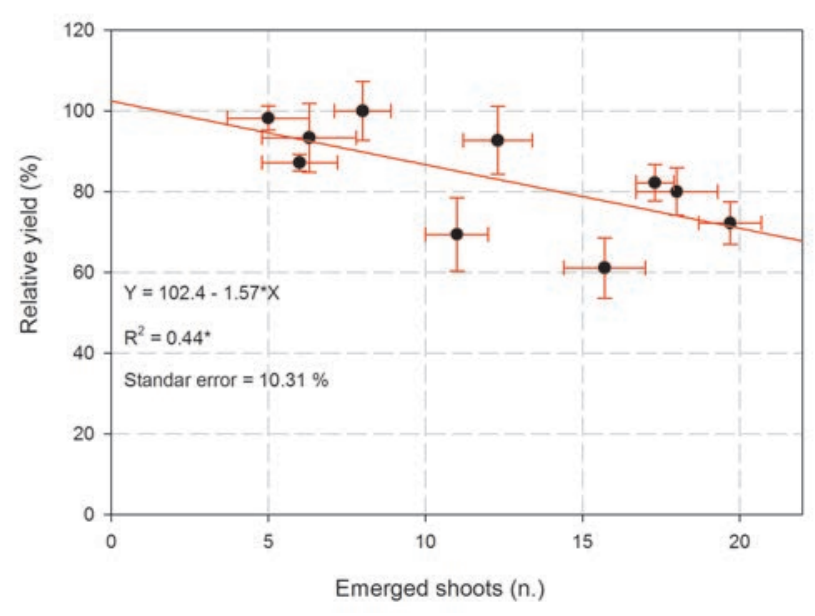

Figure 4. Relationship between tomato relative marketable yield and number of emerged Phelipanche ramosa shoots at 88 days after transplantation. Data are means \pm vertical and horizontal standard errors $(n=3)$. 
Table 2. Quanti-qualitative traits of the single tomato cultivar fruit under the different treatments.

\begin{tabular}{|c|c|c|c|c|c|c|c|c|c|c|c|}
\hline Parameter & & & & & Treatments & & & & & & Sign. \\
\hline & $\mathrm{T}_{1}$ & $\mathrm{~T}_{2}$ & $\mathrm{~T}_{3}$ & $\mathrm{~T}_{4}$ & $\mathrm{~T}_{5}$ & $\mathrm{~T}_{7}$ & $\mathrm{~T}_{10}$ & $\mathrm{~T}_{11}$ & $\mathrm{~T}_{12}$ & $\mathrm{~T}_{13}$ & \\
\hline Marketable yield $\left(\mathrm{kg} \mathrm{plant}^{-1}\right)^{\circ}$ & $1.67 \pm 0.17$ & $1.63 \pm 0.10$ & $1.44 \pm 0.12$ & $1.73 \pm 0.09$ & $1.77 \pm 0.06$ & $1.53 \pm 0.07$ & $1.80 \pm 0.15$ & $1.68 \pm 0.17$ & $1.25 \pm 0.18$ & $1.21 \pm 0.15$ & ns \\
\hline Mean fruit weight (g) & $51.33 \pm 0.79^{\mathrm{ab}}$ & $51.43 \pm 1.77^{\mathrm{ab}}$ & $60.10 \pm 0.68^{a}$ & $63.80 \pm 2.77^{\mathrm{a}}$ & $50.16 \pm 5.03^{\mathrm{ab}}$ & $44.90 \pm 3.78^{b}$ & $61.50 \pm 4.13^{a}$ & $59.60 \pm 3.20^{\mathrm{a}}$ & $49.96 \pm 2.45^{\mathrm{ab}}$ & $42.93 \pm 1.27^{b}$ & $* * *$ \\
\hline Colour coordinate (L) & $38.86 \pm 0.63^{\mathrm{ab}}$ & $39.63 \pm 0.41^{\mathrm{ab}}$ & $39.46 \pm 1.08^{a b}$ & $40.42 \pm 1.36^{\mathrm{ab}}$ & $39.98 \pm 1.09^{\mathrm{ab}}$ & $42.20 \pm 1.00^{\mathrm{a}}$ & $40.93 \pm 1.89^{\mathrm{ab}}$ & $41.24 \pm 1.40^{\mathrm{a}}$ & $42.33 \pm 0.80^{\mathrm{a}}$ & $35.49 \pm 2.08^{b}$ & $*$ \\
\hline Colour index (a/b ratio) & $1.11 \pm 0.04$ & $1.06 \pm 0.04$ & $1.05 \pm 0.03$ & $0.99 \pm 0.11$ & $1.08 \pm 0.07$ & $1.10 \pm 0.05$ & $1.03 \pm 0.09$ & $1.13 \pm 0.02$ & $0.96 \pm 0.11$ & $1.10 \pm 0.04$ & ns \\
\hline Soluble solids content ( $\left.{ }^{\circ} \mathrm{Brix}\right)$ & $4.36 \pm 0.13$ & $3.63 \pm 0.33$ & $4.36 \pm 0.14$ & $3.93 \pm 0.17$ & $4.26 \pm 0.43$ & $3.76 \pm 0.14$ & $4.00 \pm 0.15$ & $4.46 \pm 0.26$ & $3.96 \pm 0.03$ & $4.53 \pm 0.12$ & ns \\
\hline Dry matter (\% fresh matter) & $6.69 \pm 0.27^{\mathrm{a}}$ & $5.31 \pm 0.21^{b}$ & $5.95 \pm 0.03^{\mathrm{ab}}$ & $5.59 \pm 0.16^{\mathrm{ab}}$ & $6.17 \pm 0.33^{\mathrm{ab}}$ & $5.63 \pm 0.25^{\mathrm{ab}}$ & $5.85 \pm 0.30^{\mathrm{ab}}$ & $5.22 \pm 0.05^{b}$ & $5.81 \pm 0.15^{\mathrm{ab}}$ & $6.13 \pm 0.27^{\mathrm{ab}}$ & $* *$ \\
\hline
\end{tabular}

$34.53 \%$ of the total variance) was mainly related to the mean marketable yield and the mean fruit weight (scores, 0.84 and 0.85 , respectively), and thus it can be considered a quantity factor. For the quality factor (i.e., factor 1), the means were significantly higher for $\mathrm{T}_{1}, \mathrm{~T}_{5}$ and $\mathrm{T}_{13}$ (Figure 5). These treatments thus show good qualitative effects on the tomato fruit, particularly compared to treatments $\mathrm{T}_{2}, \mathrm{~T}_{7}$ and $\mathrm{T}_{12}$. For the quantity factor (i.e., factor 2), there were positive effects of $\mathrm{T}_{4}, \mathrm{~T}_{10}$ and $\mathrm{T}_{11}$ on this qualitative component, compared to the control treatment (i.e., $\mathrm{T}_{4}, \mathrm{~T}_{10}$ and $\mathrm{T}_{11}$ are positioned distant from $\mathrm{T}_{1}, \mathrm{~T}_{5}$ and $\mathrm{T}_{13}$ ) (Figure 5). Thus, in general, the PCA allowed differentiation between two groups of the experimental treatments: the first $\left(\mathrm{T}_{1}, \mathrm{~T}_{5}\right.$ and $\left.\mathrm{T}_{13}\right)$ positively influenced the quality of the tomato fruit, while the second $\left(\mathrm{T}_{4}, \mathrm{~T}_{10}\right.$ and $\left.\mathrm{T}_{11}\right)$ positively influenced the yield components.

\section{Discussion}

Significant effects for the reduction of the total number of $P$. ramosa plants were observed for the treatments with the Radicon ${ }^{\circledR}$ biostimulant $\left(\mathrm{T}_{5}\right)$ (Radicon, Inc., Elk Grove Village, IL, USA), the compost inoculated with $F$. oxysporum $\left(\mathrm{T}_{7}\right)$, and the addition of nitrogen $\left(\mathrm{T}_{11}\right)$ or sulphur $\left(\mathrm{T}_{10}\right)$, compared to the control $\left(\mathrm{T}_{13}\right)$. The Radicon ${ }^{\circledR}$ (Radicon, Inc.) biostimulant $\left(\mathrm{T}_{5}\right)$ is a suspension-solution that contains humic substances, and when this was applied to the soil, there was a marked reduction in the number of shoots of the parasitic $P$. ramosa that emerged. In terms of the specific effect of this biostimulant in the control of $P$. ramosa, there are at present no indications reported in the literature. However, it has been demonstrated that such humic substances can influence the physical, chemical and biological properties of soil, to sustain plant growth, and to affect the root exudation profile, and the primary and secondary root metabolism (Canellas and Olivares, 2014). Therefore, the reduction in the $P$. ramosa parasite incidence by application of this natural stimulant Radicon ${ }^{\circledR}$ (Radicon, Inc.) into the root zone might be due to a mechanism that includes negative effects on $P$. ramosa seed germination. In this regard, it has been reported that certain natural amino acids introduced into a crop rhizosphere can result in severe physiological disorders of the germination of $P$. ramosa seeds, with a reduction seen for the number of developing tubercles of this parasite (Vurro et al., 2005). Therefore, the use of organic products in the open field, such as Radicon ${ }^{\circledR}$ (Radicon, Inc.), as well as ensuring good organic nutrition for the tomato crop, which can reduce shoots emergence of $P$. ramosa, should be promoted for organic cultivation.

For the biological method where the soil was treated directly with $F$. oxysporum isolated from diseased $P$. ramosa plants as the only agent
Table 3. Varimax rotated factor matrix of the principal component analysis.

\begin{tabular}{lcc} 
Original variable & Factor 1 & Factor 2 \\
Marketable yield & 0.008 & 0.841 \\
Mean fruit weight & -0.152 & 0.852 \\
\hline Colour coordinate (L) & -0.649 & 0.197 \\
Colour index (a*/b* ratio) & 0.691 & -0.002 \\
\hline Soluble solids content & 0.757 & 0.104 \\
Dry matter & 0.668 & 0.163 \\
\hline Percentage explained variation & 39.71 & 34.53 \\
Cumulate explained variation & 39.71 & 74.24 \\
\hline
\end{tabular}

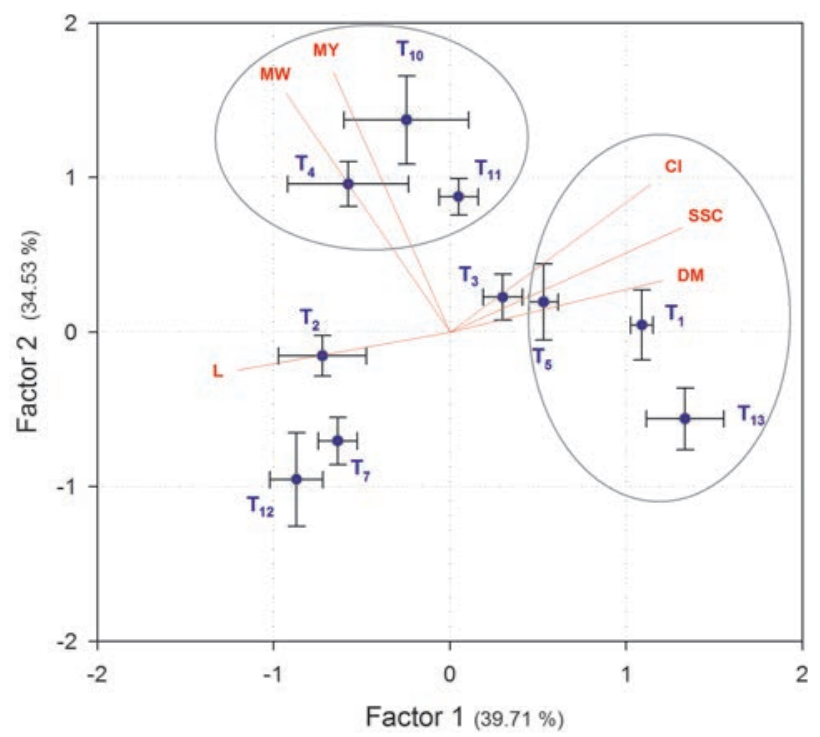

Figure 5. Principal component analysis of the qualitative parameters of the tomato fruit. Data are means \pm standard errors $(n=3)$. MY, marketable yield; MW, mean fruit weight; CI, colour index (a/b ratio); SSC, soluble solids content; DM, dry matter; L, color coordinate; T1-T13, treatments. 
used $\left(\mathrm{T}_{1}\right)$, this did not show any reduction in the number of $P$. ramosa shoots. In contrast, for the treatment with the compost activated by $F$. oxysporum $\left(\mathrm{T}_{7}\right)$, this was efficient in reducing infection, through minimising the number of parasitic shoots on the host tomato plants. This might be due to an additive effect of the organic compounds and the soil-borne $F$. oxysporum fungi on the seed germination of the $P$. ramosa parasite. This is in agreement with earlier studies that examined $F$ oxysporum (Abouzeid et al., 2004; Magdoff and Weil, 2004; Rubiales, 2012).

As agronomic management practices, high levels of nitrogen fertiliser $\left(80 \mathrm{~kg} \mathrm{ha}^{-1}\right.$ nitrogen, in addition to normal fertilising) or sulphur fertiliser ( $8 \mathrm{t} \mathrm{ha}^{-1}$ sulphur) applied prior to transplantation of the tomato seedlings showed suppressive effects on the germination, and consequently the infestation rates, of the $P$. ramosa. Similar results were reported in previous studies on tomato (Mariam and Rungsit, 2004) and on eggplant and potato (Haidar and Sidahmed, 2006).

The cv. Red setter tilling $\left(\mathrm{T}_{8}\right)$ promoted lower numbers of emerged shoots of the parasitic $P$. ramosa than for $\mathrm{cv}$. Red setter $\left(\mathrm{T}_{6}\right)$. This strategy for resistance to $P$. ramosa was also proposed as an alternative approach by Qasem and Kasrawi (1995).

In the present study, the use of tomato plants of cv. Taylor colonised by mycorrhizal fungi $\left(\mathrm{T}_{9}\right)$ did not provide any reduction in the $P$. ramosa parasite compared to the control plants. These results are in contrast with other studies on tomato that have shown lower germination of $P$. ramosa parasite seeds due to the lower amounts of stigolanctones in the root exudates of the colonised plants (Joneyama et al., 2009; Fernandez-Aporicio et al., 2009). This difference might be due to different types of stigolanctones and different quantities that are produced by any single plant species, and also by the different varieties within the same species (El-Halmouch and Thalouam, 2006; Lopez-Ráez et al., 2008; Awad et al., 2006; Xie et al., 2007).

Considering the well-known relationship between SPAD values and nutritional status of plants (especially for nitrogen) (Dwyer et al., 1995; Giunta et al., 2002; Miceli et al., 2009), the higher SPAD values of the uninfected tomato plants that were seen at 53 DAT, with respect to those that were infected, confirm the stress status induced in these parasitised tomato plants. The loss of this significant difference in the SPAD value for the late tomato growing period (i.e., at 76 DAT) can be ascribed to the effects of the different genotypes used in this study and the growth stage of the tomato crop, which corresponds to the senescence phase. This will be because chlorophyll might be related not only to direct nitrogen adsorption by the plants, but also to numerous environmental factors (e.g., drought conditions, low temperatures) and physiological factors (e.g., disease, stress of various kinds), and also the different responses of the different cultivars.

Some positive marketable yield results were obtained considering only the homogeneous treatments with the same cv. Docet. Similar results have also been reported for processing tomatoes in another study (Montemurro and Fracchiolla, 2013). Also, tomato cv. Red setter tilling gave a higher marketable yield than cv. Red setter, in agreement with the lower parasitic attack on the plant. This higher marketable yield appears to be mainly due to the higher mean weight of the fruit. For the other fruit characteristics, in general, significant differences were noted only for the colour and the dry matter content.

\section{Conclusions}

In view of the importance of processing tomatoes as a major cash crop for farmers and the heavy losses in the field that are mainly due to $P$. ramosa infestation in the Apulia region (southern Italy), it is very important to select the best method for the control of this harmful weed. The search for sustainable methods for controlling this parasite has also become increasingly important.

The main conclusion that can be drawn from the present study is the demonstration that no single technique provides complete control of $P$. ramosa, and that it is thus not possible to avoid resorting to these methods. Indeed, some of these methods are particularly suitable, such as soil application of the Radicon ${ }^{\circledR}$ biostimulant (Radicon, Inc.), high levels of nitrogen or sulphur fertilisers, compost activated with $F$. oxysporum, and the use of resistant tomato cultivars. These appear to be the most effective methods for the reduction of infestations of this $P$. ramosa parasitic weed for processing tomato crops. It can also be assumed that these beneficial effects can be improved by combining some of these treatments with each other, especially in terms of providing a gradual and continuing reduction of the seed bank of the $P$. ramosa parasite in the soil.

Based on the results of the present study, we would suggest that the agronomic, biological and biotechnological methods that preclude chemical contamination and are suitable also for organic crop systems are the appropriate methods to reduce the risk of $P$. ramosa infestation. However, more investigations need to be carried out with further integrated methods for the control of this $P$. ramosa parasite in processing tomato crops.

\section{References}

Abouzeid MA, Boari MC, Zonno M, Vurro M, Evidente A, 2004. Toxicity profiles of potential biocontrol agents of Orobanche ramosa. Weed Sci. 52:326-32.

Abouzeid MA, El-Tarabil KA, 2010. Fusarium spp. suppress germination and parasitic establishment of bean and hemp broomrapes. Phytopathol. Mediterr. 49:51-64.

Abu-Irmaileh BE, 1981. Response of hemp broomrape (Orobanche ramosa) infestation to some nitrogenous compounds. Weed Sci. 29:8-10.

Alfano G, Lustrato G, Lima G, Vuitullo D, Ranalli G, 2011. Characterization of composted olive mill wastes to predict potential plant disease suppressiveness. Biol. Contr. 58:199-207.

Amsellem ZY, Barghouthi S, Cohen B, Goldwasser Y, Gressel J, Hornok L, Kerenyi Z, Kleifeld Y, Klein 0, Kroschel J, Sauerborn J, MüllerStöver D, Thomas H, Vurro M, Zonno M-C, 2001. Recent advances in the biocontrol of Orobanche (broomrape) species. BioControl 46:211-28.

AOAC, 1990. Official method of analysis (No 934,06). Association of Official Analytical Chemists (AOAC), Washington, DC, USA.

Awad AA, Sato D, Kusumoto D, Kamioka H, Takeuchi Y, Yoneyama K, 2006. Characterization of strigolactones, germination stimulants for the root parasitic plants Striga and Orobanche, produced by maize, millet and sorghum. Plant Growth Regul. 48:221-7.

Azam IE, Abouzeid MA, Boari A, Vurro M, Evidente A, 2003. Identification of phytotoxic metabolites of a new Fusarium species inhibiting germination of Striga hermonthica seeds. Phytopathol. Mediterr. 42:65-70.

Bebawi FF, 1981. Response of Sorghum bicolor cultivars and Striga hermonthica population to nitrogen fertilization. Plant Soil 59:261-8.

Boari A, Vurro M, 2004. Evaluation of Fusarium spp. and other fungi as biological control agents of broomrape (Orobanche ramosa). Biol. Contr. 30:212-9.

Buchanan GA, Hoveland CS, Harris MC, 1975. Response of weeds to soil pH. Weed Sci. 23:473-7.

Caliandro A, Lamaddalena N, Stelluti M, Steduto P, 2005. Caratterizzazione agro-ecologica della Regione Puglia in funzione 
della potenzialità produttiva. Progetto ACLA. Ideaprint, Bari, Italy.

Canellas L, Olivares FL, 2014. Physiological responses to humic substances as plant growth promoter. Chem. Biol. Technol. Agric. 6:1-3.

Cubero JI, Moreno MT, 1979. Agronomical control and sources of resistance in Vicia faba to 0. crenata. In: D.A. Bond, G.T. ScarasciaMugnozza, M.H. Poulsen (Eds.), Some current research on Vicia faba in western Europe, Commission of the European Communities, Brussels, Belgium, pp. 41-80.

Disciglio G, Gatta G, Libutti A, Gagliardi A, Carlucci A, Lops F, Cibelli F, Tarantino A, 2015. Effects of irrigation with treated agro-industrial wastewater on soil chemical characteristics and fungal populations during processing tomato crop cycle. J. Soil Sci. Plant Nutrit. [In press].

Dor E, Evidente A, Amalfitano C, Agrelli D, Hershenhorn J, 2007. The influence of growth conditions on biomass, toxins and pathogenicity of Fusarium oxysporum f. sp. orthoceras, a potential agent for broomrape control. Weed Res. 47:345-52.

Dor E, Alperin B, Wininger S, Ben-Dor B, Somvanshi VS, Koltai H, Kapulnik Y, Hershenhorn J, 2010. Characterization of a novel tomato mutant resistant to the weedy parasites Orobanche and Phelipanche spp. Euphytica 171:371-80.

Dwyer LM, Anderson AM, Ma BL, Stewart DW, Tollenaar M, Gregorich E, 1995. Quantifying the nonlinearity in chlorophyll meter response to corn leaf nitrogen concentration. Can. J. Plant Sci. 75:179-82.

Eizenberg H, Tanaami Z, Ovdat N, Rubin B, Jacobsohn R, 1998. Effect of seasonal conditions on host-parasite relationship in Orobanche crenata and 0. aegyptiacal. In: K. Wegmann, L.J. Muselman, D.M. Joel (Eds.) Current problems in Orobanche research. Proc. $4^{\text {th }}$ Int. Workshop Orobanche, Bulgaria, pp. 187-92.

El-Halmouch Y, Thalouam P, 2006. Effect of root exudates from different tomato genotypes on broomrape (0. aegyptiaca) seed germination and tubercle development. Crop Prot. 25:501-7.

Favati F, Lovelli S, Galgano F, Miccolis V, Di Tommaso T, Candido V, 2009. Processing tomato quality as affected by irrigation scheduling. Scient. Horticult. 122:562-71.

Fernandez-Aparicio M, Flores F, Rubiales D, 2009. Recognition of root exudates by seeds of broompare (Orobanche and Phelipanche) species. Ann. Bot. 103:423-31.

Francis FJ, Clydesdale FM, 1975. Food colorimetry: theory and applications. AVI Publ. Co., Westport, CT. pp. 477.

Giunta F, Motzo R, Deidda M, 2002. SPAD readings and associated leaf traits in durum wheat, barley and triticale cultivars. Euphytica 125:197-205.

Goldwasser Y, Kleifeld Y, 2004. Recent approaches to Orobanche management, a review. In: Enderjit (Ed.) Weed biology and management, Kluwer Academic Publishers, Germany, pp. 439-66.

Goldwasser Y, Rodenburg J, 2013. Integrated agronomic management of parasitic weed seed banks. In: D.M. Joel, J. Gressel, L.J. Musselman (Eds.), Parasitic Orobanchacee. Parasitic mechanisms on control strategies. Springer-Verlag, Berlin, Germany, pp. 393413.

Gressel J, 2013. Biotechonologies for directly generating crop resistant to parasite. In: D.M. Joel, J. Gressel, L.J. Musselman (Eds.), Parasitic Orobanchaceae. Parasitism mechanisms on control strategies. Springer-Verlag, Berlin, Germany, pp. 433-458.

Habimana S, Murthy KNK, Hatti V, Nduwumuremyi A, 2013. Management of Orobanche in field crops. A review. Sci. J. Crop Sci. 2:144-58.

Haidar MA, Sidahmed MM, 2000. Soil solarization and chicken manure for the control of Orobanche crenata and other weeds in Lebanon. Crop Prot. 19:169-73.

Haidar MA, Sidahmed MM, 2006. Elemental sulphur and chicken manure for the control of branched broomrape (Orobanche ramosa). Crop Prot. 25:47-51.

Italian Regulation, 1996. Legge 11 novembre 1996, n. 574. Nuove norme in materia di utilizzazione agronomica delle acque di vegetazione e di scarichi dei frantoi oleari. In: G.U. n. 265, 12/11/1996, available from: http://www.camera.it/parlam/leggi/96574l.htm

Jamil M, Charnikhova T, Cardoso C, Jamil T, Ueno K, Verstappen F, Asami T, Bouwmeester HJ, 2011. Quantification of the relationship between strigolactones and Striga hermonthica infection in rice under varying levels of nitrogen and phosphorus. Weed Res. 51:373-85.

Jiménez-Cuesta M, Cuquarella J, Martinez-Javaga JM, 1981. Determination of color index for citrus fruit degreening. Proc. Int. Citricult. 2:750-3.

Joel DM, 2000. The long-term approach to parasitic weed control, manipulation of specific developmental mechanisms of the parasite. Crop Prot. 19:753-8.

Joel DM, Hershenhorn J, Eizenberg H, Aly R, Ejeta G, Rich JP, Ransom JK, Saurborn J, Müller-Stöver D, Hershenhorn J, 2007. The role of biological control in managing parasitic weeds. Crop Prot. 26:246-54.

Joneyama K, Xie X, Yoneyama K, Takfuchi Y, 2009. Stigolactones: structures and biological activities. Pest. Manag. Sci. 65:467-70.

Lendzemo VW, Kuyper TW, Matusova R, Bouwmeester HJ, Van Ast A, 2007. Colonization by arbuscular mycorrhizal fungi of sorghum leads to reduced germination and subsequent attachment and emergence of Striga hermonthica. Plant Signal. Behav. 2:1-5.

Linke KH, Saxena MC, 1989. Study on viability and longevity of Orobanche seeds under laboratory conditions. In: K. Wegmann, L.J. Musselman (Eds.), Progress in Orobanche research. EberhardKarls Universitat, Tubingen, Germany, pp. 110-4.

Litterick AM, Harrier LA, Wallace P, Watson CA, Wood M, 2004. The role of uncomposted materials, composts, manures and compost extracts in reducing pest and disease incidence and severity in sustainable temperate agricultural and horticultural crop production. A review. Crit. Rev. Plant Sci. 23:453-79.

Lombardo S, Longo AMG, Lo Monaco A, Mauromicale G, 2012. The effect of soil solarization and fumigation on pests and yields in greenhouse tomatoes. Crop Protec. 37:59-64.

Lonsdale WN, 1993. Losses from the seed bank of Mimosa pigra - soil microorganisms vs. temperature fluctuations. J. Appl. Ecol. 30:654-60.

Lopez-Ráez JA, Matusova R, Cardoso C, Jamil M, Charnikhova T, Kohlen W, Ruyter-Spira C, Verstappen F, Bouwmeester H, 2008. Stigolactones: ecological significance and use as a target for parasitic plant control. Pest. Manag. Sci. 65:471-7.

Lopez-Ráez JA, Charnikhova T, Fernandez I, Bouwmeester H, Pozo MJ, 2011. Arbuscular mycorrhizal symbiosis decreases strigolactone production in tomato. J. Plant Physiol. 168:294-7.

Magdoff F, Weil RR, 2004. Soil organic matter management strategies. In: F. Magdoff, R.R. Weil (Eds.), Soil organic matter in sustainable agriculture. CRC Press, Boca Raton, FL, USA, pp. 45-65.

Mariam EG, Rungsit S, 2004. Effect of nitrogen fertilizers on branched broomrape (Orobanche ramosa L.) in tomato (Lycopersicon esculentum Mill.). Kasetsart J. Nat. Sci. 38:311-9.

Miceli A, Moncada A, D’Anna A, 2009. Effetto della forma azotata e della modalità di distribuzione sulla produzione e la qualità della lattuga. Atti Convegno Nazionale "Orticoltura di qualità per un mercato in evoluzione", 30 Aprile, Foggia, Italy, pp. 14-15. Available from: http://orticoltura.altervista.org/pdf/abstracts.pdf

Minoia S, Petrozza A, D’Onofrio 0, Piron F, Mosca G, Sozio G, Cellini F, Bendahmane A, Carriero F, 2010. A new mutant genetic resource for tomato crop improvement by TILLING technology. BMC Res. Notes 3:69.

Montemurro P, Fracchiolla M, 2013. Caso studio delle dinamiche evolutive della vegetazione infestante e sulla gestione integrata: il caso 
della Phelipanche ramosa (L.) Pomel nel pomodoro da industria nella Capitanata. XIX Convegno SIRFI "Gestione delle malerbe nelle colture agrarie alal luce delle attuali problematiche legislative, agronomiche e ambientali”, 17 dicembre, Bologna, Italy, p. 25. Available from: http://www.sirfi.it/it/eventi/43-eventi-nazionali/96convegno-sirfi-2013-atti-e-presentazioni-online.html

Pieterse AH, 1991. The effect of nitrogen fertilizers on the germination of seeds of Striga and Orobanche crenata. In: K. Wegmann, L.J. Musselman (Eds.), Progress in Orobanche Research. EberhardKarls-Universitat, Tubengen, Germany, pp. 115-24.

Qasem JR, Kasrawi MA, 1995. Variation of resistance to broomrape (Orobanche ramosa) in tomatoes. Euphytica 81:109-14.

Rubiales D, Fernandenz-Aparicio M, 2012. Innovations in parasitic weeds management in legume crops. Agron. Sustain. Dev. 32:433-49.

Saad H, Laor Y, Raviv M, Medina S, 2007. Land spreading of olive mill wastewater. Effects on soil microbial activity and potential phytotoxicity. Chemosphere 66:75-83.

Sauerborn J, Müller-Stöver D, Hershenhorn J, 2007. The role of biological control in managing parasitic weeds. Crop Prot. 26:246-54.

Silletti MF, Petrozza A, Stigliani AL, Giorio G, Cellini F, D’Ambrosio C, Carriero F, 2013. An increase of licopene content in tomato fruit is associated to a novel Cyc-B allele isolated through TILLING technology. Mol. Breed. 31:665-74.

Tardioli S, Bannè ETG, Santoi F, 1997. Species-specific selection on soil fungal population after olive mill wastewater treatment. Chemosphere 34:2329-36.

van Mourik TA, Stomph TJ, Murdoch AJ, 2005. Why high seed densities within buried mesh bags may overestimate depletion rates of soil seed banks. J. Appl. Ecol. 42:299-305.

van Mourik TA, Stomph TJ, 2011. Purple witch weed (Striga hermonthica) germination and seed bank depletion under different crops, fallow, and bare soil. Weed Biol. Manag. 11:100-10.

Vurro M, Boari A, Pilgeram AL, Sands DC, 2005. Exogenous amino acids inhibit seed germination and tubercle formation by Orobanche ramosa (broomrape): potential application for management of parasitic weed. Biol. Contr. 36:258-65.

Westerman PR, Wes JS, Van der Kropff MJ, Werf W, 2003. Annual losses of weed seeds due to predation in organic cereal fields. J. Appl. Ecol. 40:824-36.

Xie X, Kusumoto D, Takeuchi Y, Yoneyama K, Yamada Y, Yoneyama K, 2007. 2'-Epi-orobanchol and solanacol, two unique strigolactones, germination stimulants for root parasitic weeds, produced by tobacco. J. Agric. Food Chem. 55:8067-72.

Yang H, Li J, Yang J, Wang H, Zou J, He J, 2014. Effects of nitrogen application rate and leaf age on the distribution pattern of leaf SPAD readings in the rice canopy.

Zindahl R, 1993. Fundamentals of weed science. Academic Press Inc., New York, NY, USA, pp. 499.

Zollinger RK, Kells JJ, 1991. Effect of soil pH, soil water, light intensity and temperature on perennial sowthistle (Sonchus arvensis L.). Weed Sci. 39:376-84.

Zonno M-C, Montemurro P, Vuerro M, 2000. Orobanche ramosa, un'infestante parassita in espansione nell'Italia meridionale. L'Inf. Agr. 4:13-21.

Zonno M-C, Vurro M, 2002. Inhibition of germination of Orobanche ramosa seeds by Fusarium toxins. Phytoparasitica 30:519-24. 